\title{
Genomic organization, annotation, and ligand-receptor inferences of chicken chemokines and chemokine receptor genes based on comparative genomics
}

\author{
Jixin Wang1, David L Adelson ${ }^{2}$, Ahmet Yilmaz ${ }^{1}$, Sing-Hoi Sze ${ }^{3}$, Yuan Jin ${ }^{3}$ and \\ James J Zhu*1
}

Address: ${ }^{1}$ Department of Poultry Science, Texas A \& M University, College Station, TX 77843, USA, ${ }^{2}$ Department of Animal Science, Texas A \& M University, College Station, TX 77843, USA and ${ }^{3}$ Department of Computer Science, Texas A \& M University, College Station, TX 77843, USA

Email: Jixin Wang - jixinwang@tamu.edu; David L Adelson - david.adelson@tamu.edu; Ahmet Yilmaz - ahmetyilmaz22@yahoo.com; SingHoi Sze - shsze@tamu.edu; Yuan Jin - yuan-jin@tamu.edu; James J Zhu* - jzhu@poultry.tamu.edu

* Corresponding author

Published: 24 March 2005

BMC Genomics 2005, 6:45 doi:10.1 186/147|-2/64-6-45

This article is available from: http://www.biomedcentral.com/I47/-2/64/6/45

(c) 2005 Wang et al; licensee BioMed Central Ltd.

This is an Open Access article distributed under the terms of the Creative Commons Attribution License (http://creativecommons.org/licenses/by/2.0), which permits unrestricted use, distribution, and reproduction in any medium, provided the original work is properly cited.

\begin{abstract}
Background: Chemokines and their receptors play important roles in host defense, organogenesis, hematopoiesis, and neuronal communication. Forty-two chemokines and 19 cognate receptors have been found in the human genome. Prior to this report, only II chicken chemokines and 7 receptors had been reported. The objectives of this study were to systematically identify chicken chemokines and their cognate receptor genes in the chicken genome and to annotate these genes and ligand-receptor binding by a comparative genomics approach.
\end{abstract}

Results: Twenty-three chemokine and 14 chemokine receptor genes were identified in the chicken genome. All of the chicken chemokines contained a conserved $\mathrm{CC}, \mathrm{CXC}, \mathrm{CX}_{3} \mathrm{C}$, or XC motif, whereas all the chemokine receptors had seven conserved transmembrane helices, four extracellular domains with a conserved cysteine, and a conserved DRYLAIV sequence in the second intracellular domain. The number of coding exons in these genes and the syntenies are highly conserved between human, mouse, and chicken although the amino acid sequence homologies are generally low between mammalian and chicken chemokines. Chicken genes were named with the systematic nomenclature used in humans and mice based on phylogeny, synteny, and sequence homology.

Conclusion: The independent nomenclature of chicken chemokines and chemokine receptors suggests that the chicken may have ligand-receptor pairings similar to mammals. All identified chicken chemokines and their cognate receptors were identified in the chicken genome except CCR9, whose ligand was not identified in this study. The organization of these genes suggests that there were a substantial number of these genes present before divergence between aves and mammals and more gene duplications of CC, CXC, CCR, and CXCR subfamilies in mammals than in aves after the divergence. 


\section{Background}

Chemokines are a family of small chemoattrative peptides that were originally recognized to be involved in host defense as regulators of leukocyte trafficking, but more recently have also been shown to have roles in organogenesis, hematopoiesis, and neuronal communication [1]. Their cognate receptors belong to the Class A subfamily of G-protein coupled receptor superfamily [2]. Chemokines are believed to have originated from gene duplications and these genes underwent selection during recent evolutionary time [3]. All chemokines have a characteristic cysteine motif. Similarly, chemokine receptors may also be derived from a common ancestor through gene duplications. All chemokine receptors share high homology with the prototypical family member, rhodopsin [2].

Chemokines are highly basic proteins, 70 to 125 amino acids long. Sequence identity among chemokines is usually low; however, all share a typical overall tertiary structure, which consists of at least four cysteines that form two disulfide bonds. Chemokines are divided into two major (CC and CXC) and two minor ( $\mathrm{XC}$ and $\mathrm{CX}_{3} \mathrm{C}$ ) subfamilies based on their four conserved cysteines. The first two cysteines in the two major subfamilies are either adjacent (CC) or separated by one amino acid (CXC). The first two cysteines in the $\mathrm{CX}_{3} \mathrm{C}$ chemokines are separated by three amino acids, whereas the XC chemokines contain only two of the cysteines [4]. The CC chemokines can be further divided into two subcategories, MCPs (monocyte chemoattractant proteins) and MIPs (macrophage inflammatory proteins) based on their structural similarities [5]. The members of these two CC subcategories specifically attract mononuclear cells but not neutrophils. The CXC chemokines can also be divided into two subfamilies, one with an ELR (a conserved Glu-Leu-Arg preceding the first cysteine) motif, which is angiogenic and attracts neutrophils, and the other without the ELR motif, whose members do not attract neutrophils [6].

Chemokine genes are characterized by their chromosomal locations and similar gene structure. Most human CC and CXC genes are organized in gene clusters in mammalian genomes, such as human Chromosomes 4 and 17, and mouse Chromosomes 5 and 11 [7]. The genes encoding the CC subfamily contain three exons, whereas the CXC chemokine genes contain four exons $[8,9]$. The XC subfamily of chemokines contains two members in human but only one in mouse. $\mathrm{CX}_{3}$ CL1 is the only known member of the $\mathrm{CX}_{3} \mathrm{C}$ subfamily in human, mouse, rat, and monkey. There are extensive conserved syntenies in the chromosomal regions containing chemokine genes between human and mouse.

Unlike chemokines, chemokine receptors share a higher degree of sequence identity within a species and between species. These receptors have characteristic seven alphahelix transmembrane domains with a length between $340-370$ amino acids and have up to $80 \%$ amino acid identity [1]. They also share an acidic amino terminus, a conserved sequence in the second intracellular loop, and one cysteine in each extracellular domain [10]. Most receptors can bind several chemokines of a single class with high affinity [11]. Like chemokines, most chemokine receptors are also clustered in a few chromosomal regions, such as human Chromosomes 2 and 3 [2]. Most amino acid sequences of chemokine receptors are encoded in one exon.

At present, 42 chemokine genes have been identified in human (24 CC, $15 \mathrm{CXC}, 1 \mathrm{CX}_{3} \mathrm{C}$, and $2 \mathrm{XC}$ ) and 36 (21 $\mathrm{CC}, 13 \mathrm{CXC}, 1 \mathrm{CX}_{3} \mathrm{C}$, and $1 \mathrm{XC}$ ) in mouse, whereas there are 11 receptors for CCLs, 6 for CXCLs, 1 for $\mathrm{CX}_{3} \mathrm{CL}$, and 1 for XCL in human and mouse. Only 11 chicken chemokines including 4 CXC, 6 CC, and $1 \mathrm{XC}$ and seven chicken chemokine receptors including 2 CXCR and 5 CCR have been reported in the literature [12-23]. Chicken chemokines share low sequence identity with mammals [24]. Therefore, it was very difficult to assign chicken chemokines to a specific mammalian counterpart based on sequence data alone. Because of limited sequence similarity, most of the reported chicken chemokines were not named in accordance with the systematic nomenclature of mammalian chemokines. The newly available chicken draft genome sequence and a large number ESTs allow systematic identification and annotation of chicken chemokine and cognate receptor genes. The objectives of this study were to systematically identify chemokine and chemokine receptor genes in the chicken genome, to name these genes according to existing systematic nomenclature, and to make ligand-receptor binding inferences based on comparative sequence analysis. The systematic nomenclature for these chicken genes was based on the phylogenetic trees and syntenies of chicken, human, and mouse genes, and ligand-receptor binding inferences were according to [37] and [38].

\section{Results \\ Chicken chemokines and chemokine receptors}

In addition to the 11 previously reported, 12 new chicken chemokine were identified. These include 7 new CC chemokines named CCL1L1 (BX935885), CCL3L1 (CF258095), CCL/MCP-L2 (CK610423), CCL/MCP-L3 (CK610627), CCL17 (BI067703), CCL19 (BX929857), and CCL21 (CR522995), 4 new chicken CXC chemokines named CXCL13a (BX262175), CXCL13b (BX264625), and CXCL13C (CR352598), CXCL15 (BX929947), and 1 $\mathrm{CX}_{3} \mathrm{CL} 1$ chemokine (assembled from CR389767, BI066258, BM426140, and our sequence: AY730688). Eleven reported chicken genes were also named accordingly as CCL1L2 (L34552), CCL5 (ah294, AY037859), 


\author{
CCCL1L1 \\ CCCL1L2 \\ CCCL3L1 \\ CCCL4L1 \\ CCCL 5 \\ CCCL/MCP-L3 \\ CCCL/MCP-L1 \\ CCCL/MCP-L2 \\ CCCL16 \\ CCCL17 \\ CCCL19 \\ CCCL20 \\ CCCL2 1 \\ CCCL1L1 \\ CCCL1L2 \\ CCCL3L1 \\ CCCL4L1 \\ CCCL5 \\ CCCL/MCP-L3 \\ CCCL/MCP-L1 \\ CCCL/MCP-L2 \\ CCCL16 \\ CCCL17 \\ CCCL19 \\ CCCL20 \\ CCCL2 1
}

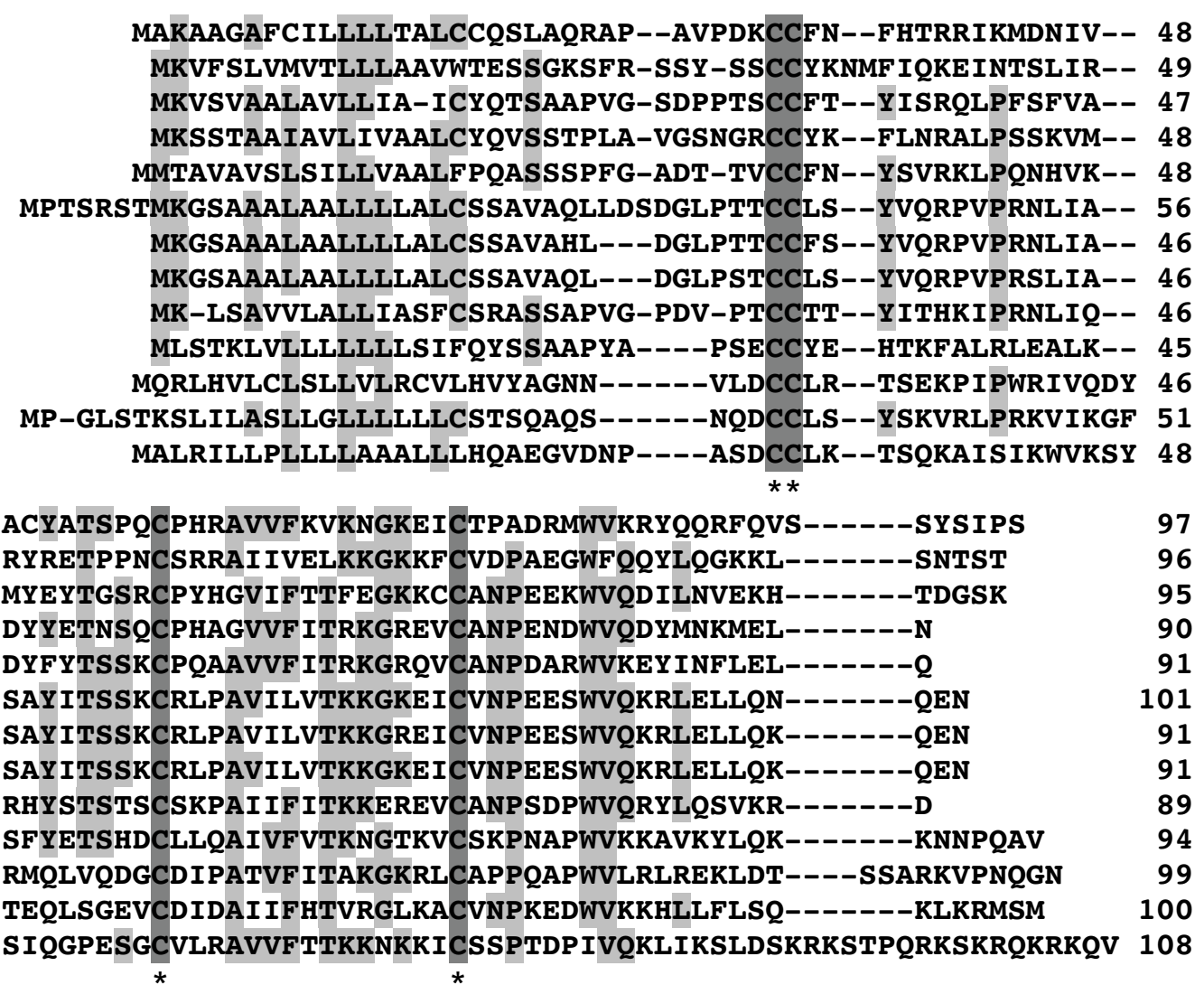

MAKAAGAFCILLLLTALCCQSLAQRAP--AVPDKCCFN--FHTRRIKMDNIV-- 48 MKVFSLVMVTLLLAAVWTESSGKSFR-SSY-SSCCYKNMF IOKEINTSLIR-- 49 MKVSVAALAVLLIA-ICYQTSAAPVG-SDPPTSCCFT--YISRQLPFSFVA-- 47 MKSSTAAIAVLIVAALCYQVSSTPLA-VGSNGRCCYK--FLNRALPSSKVM-- 48 MMTAVAVSLS ILLVAALF PQASSSPFG-ADT-TVCCFN--YSVRKLPQNHVK-- 48 MKGSAAALAALLLLALCSSAVAOL---DGLPSTCCLS--YVORPVPRSLIA-- 46 MK-LSAVVLALLIASFCSRASSAPVG-PDV-PTCCTT--YITHKIPRNLIQ-- 46 MLSTKLVLLLLLLLSIFQYSSAAPYA----PSECCYE--HTKFALRLEALK-- 45 MORLHVLCLSLLVLRCVLHVYAGNN------VLDCCLR--TSEKPI PWRIVQDY 46 TKSLILASLLGLLLLLLCSTSOAOS------NODCCLS--YSKVRLPRKVIKGF 51 MALRILLPLLLLAAALLLHQAEGVDNP-

$\begin{array}{lr}\text { ACYATSPQCPHRAVVFKVKNGKEICTPADRMWVKRYQQRFQVS------SYSIPS } & 97 \\ \text { RYRETPPNCSRRAI IVELKKGKKFCVDPAEGWFQQYLQGKKL-------SNTST } & 96 \\ \text { MYEYTGSRCPYHGVIFTTFEGKKCCANPEEKWVQDILNVEKH-------TDGSK } & 95 \\ \text { DYYETNSQCPHAGVVF ITRKGREVCANPENDWVQDYMNKMEL-------N } & 90 \\ \text { DYFYTSSKCPQAAVVFITRKGRQVCANPDARWVKEYINFLEL-------Q } & 91 \\ \text { SAYITSSKCRLPAVILVTKKGKEICVNPEESWVQKRLELLQN-------QEN } & 101 \\ \text { SAYITSSKCRLPAVILVTKKGREICVNPEESWVQKRLELLQK-------QEN } & 91 \\ \text { SAYITSSKCRLPAVILVTKKGKEICVNPEESWVQKRLELLQK-------QEN } & 91 \\ \text { RHYSTSTSCSKPAIIFITKKEREVCANPSDPWVQRYLQSVKR-------D } & 89 \\ \text { SFYETSHDCLLQAIVFVTKNGTKVCSKPNAPWVKKAVKYLQK-------KNNPQAV } & 94 \\ \text { RMQLVQDGCDIPATVF ITAKGKRLCAPPQAPWVLRLREKLDT----SSARKVPNQGN } & 99 \\ \text { TEQLSGEVCDIDAIIFHTVRGLKACVNPKEDWVKKHLLFLSQ-------KLKRMSM } & 100 \\ \text { SIQGPESGCVLRAVVFTTKKNKKICSSPTDPIVQKLIKSLDSKRKSTPQRKSKRQKRKQV } & 108 \\ \text { * } & \text { * }\end{array}$

Figure I

Alignment of amino acid sequences of chicken chemokine CC subfamily. Alignment gaps are indicated by dashes. Sequences with identical amino acid in at least $50 \%$ of chicken chemokines are highlighted in gray and conserved cysteine residues in dark gray.

CCL4L1 (MIP-1 $\beta$, AJ243034), CCL/MCP-L1 (ah221, AY037860/ BX933162), CCL16 (k203, Y18692), CCL20 (ah189, AY037861), CXCL8a (cCAF, M16199), CXCL8b (K60, Y14971), CXCL12 (SDF-1, BX936268), CXCL14 (JSC, AF285876), and XCL1 (lymphotactin, AF006742). In summary, there are $13 \mathrm{CCL}, 8 \mathrm{CXCL}, 1 \mathrm{CX}_{3} \mathrm{CL}$, and 1 $\mathrm{XCL}$ genes identified in the chicken genome. The information used for the nomenclature is shown in the comparative genomic maps and phylogenetic trees.

Chicken chemokine amino acid sequence alignment shows that all chicken CC chemokines have four conserved cysteines with two adjacent cysteines at the N-terminus (Figure 1), whereas all chicken CXC chemokines have the conserved four cysteines with the first two cysteines separated by one amino acid (Figure 2). Both chicken CCLs and CXCLs show higher degrees of sequence similarity to each other in the signal peptide sequences and sequence regions containing the last two cysteines. Chicken CXCL8a, CXCL8b, and newly identified chemokine CXCL15 contain the ELR (Glu-Leu-Arg) motif. Only one chicken $\mathrm{CX}_{3} \mathrm{C}$ chemokine was found (Figure 3). The number of amino acid residues between conserved cysteines in all chemokines is highly conserved between chicken and human (Table 1).

Chicken chemokines have limited amino acid sequence similarity compared to their human counterparts. Generally, chicken CXC chemokines share 27 to $60 \%$ amino acid identity with their human homologs except for CXCL12, which share 73\% identity with human CXCL12. The length of chicken chemokine CXCL polypeptides ranges from 95 to 107 amino acids. Compared to their human homologs, chicken CXCL chemokine amino acid sequences are shorter except for chicken CXCL8a, CXCL8b, and CXCL12, which are 4, 5, 12 amino acids longer than their respective human homologs. In contrast, the sequence identities between human and chicken CCL 


\author{
CCXCL8b \\ CCXCL8a \\ CCXCL12 \\ CCXCL13a \\ CCXCL13b \\ CCXCL13C \\ CCXCL 15 \\ CCXCL14 \\ CCXCL8b \\ CCXCL8a \\ CCXCL12 \\ CCXCL13a \\ CCXCL13b \\ CCXCL13C \\ CCXCL15 \\ CCXCL14
}

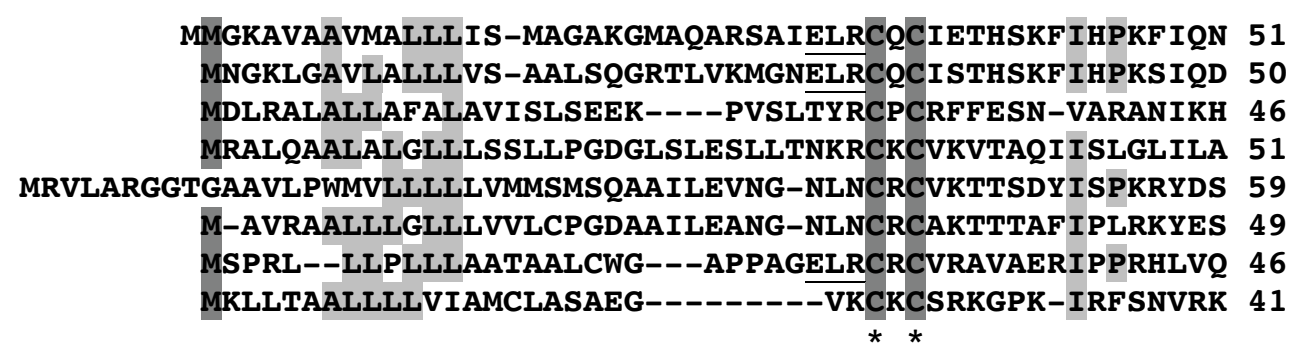

VNLTPSGPHCKNVEVIATL--K--DGREVCLDPTAPWVKLIIKAILDKADTNNKTAS 104

VKLTPSGPHCKNVEI IATL--K--DGREVCLDPTAPWVQLIVKALMAKAQLNSDAPL 103

LKILST-PNCS-LQIVARL--K-SNSKQVCIDPKLKWIQEYLEKALNKPRHRTHKKKQQK 101

IDVMPPGIHCRRKEIILTL--K--RNKKVCVAPEAPWIQLLIHKLTQTDVSKKEAAAVAR 107

IELRPVGSTCRRIEIIIKL--K--SSAKVCVNPDAPWVKKLLKRIAG 102

VEVRPVGSSCRRLEVLIKL--K--TLERICVDPNTPWVRKLLQDLPKLKKKAAPQ 100

VELVPEGPHCAAPEVIATT--K--QGHTLCLSPSVPWVKLLVARFLNSAAQRS

LEIKPRY PFCVEEMI IVTLWTKVRGEQQHCLNPKRQNTVRLLKWYRVWKEKGRVYEE 98

Figure 2

Alignment of amino acid sequences of chicken chemokine CXC subfamily. Alignment gaps are indicated by dashes. Sequences with identical amino acid in at least $50 \%$ of chicken chemokines are highlighted in gray and conserved cysteine residues in dark gray. The conserved ELR motifs are underlined.

chemokines are generally lower than those for CXCL chemokines, ranging from 25 to $56 \%$. Chicken chemokine CCL polypeptides have 89 to 108 amino acids. Chicken CCL1L2, CCL5, and CCL17 have the same amino acid length as their human counterparts. Chicken CCL4L1 is shorter than corresponding human CCL4, whereas chicken CCL1L1, CCL3L1, CCL19, and CCL20 are longer than the corresponding human CCLs. These differences in length between human and chicken chemokines are mostly in the $\mathrm{N}$ - and $\mathrm{C}$ - termini.

Chicken $\mathrm{CX}_{3} \mathrm{CL} 1$ encodes 441 amino acids, longer than all mammalian $\mathrm{CX}_{3} \mathrm{CL} 1$ examined. It shares $20,22,20$, and $22 \%$ amino acid identity with human, mouse, rat, and monkey $\mathrm{CX}_{3} \mathrm{CL} 1$, respectively. Sixty-six amino acid residues in chicken $\mathrm{CX}_{3} \mathrm{CL} 1$ are identical to residues in mammals, but the sequence identity between mammals is, as expected, much higher than that between chickens and mammals (Figure 3 ). There are more identical amino acids between chicken and mammals at both ends of the sequences.

Unlike the chemokines, all the chicken chemokine receptor genes were aligned with non-chicken chemokine receptor reference genes in the chicken genome browser. There was at least one chicken EST sequence aligned to each receptor gene except for CCR4. In addition to 7 reported receptors, 7 new chicken chemokine receptors were identified and named as CCR4 (predicted sequences:
ENSGALT00000019505.1), CCR6 (CV039916, BU451770, and CK987456), CCR7 (predicted sequence: chr27_random_59.1), CCR8a (AJ720982), CXCR2 (BX258468), CXCR5 (AJ450829), CX3CR1 (CF252942, BU204148, and AJ443633). In contrast to chicken chemokines, chicken chemokine receptors share significant amino acid identity with their human receptor counterparts. The percents of amino acid identity between chicken and human chemokine receptors range from 48 to $81 \%$. The lengths of these chicken receptors range from 335 to 382 amino acids. The complete sequence of chicken CXCR2 is unknown due to a sequence gap in the chicken genome sequence. The CXCR2 EST and a partial genome sequence contain the last 170 amino acids of the C-terminus.

Fourty-four amino acid residues were highly conservated (>85\% homologies) among all chicken chemokine receptors (Figure 4). These receptors all have seven transmembrane helices and three extracellular loops. Of the seven transmembrane helices, helix 1 and 7 show higher degrees of sequence similarity than the other helices. The similarity between the extracellular domains of the chicken receptors is lower, but all have a conserved cysteine residue. In contrast, the intracellular domains (except at the C-terminus) generally have higher degrees of sequence similarity than the extracellular domains. The second intracellular domains contain a highly conserved DRYLAIV sequence. 


\begin{abstract}
Chicken MRVASLQIPFALRVLC-LAAMAGGQPRAPLKCSKWCISFHRAIDQRQIKSYRETEPQCTK 59 Human MAPISLSWLLRLATFCHLTVLLAGQHHGVTKCNITCSKMTSKIPVALLIHYQQNQASCGK 60 Mouse MAPSPLAWLLRLAAFFHLCTLLPGQHLGMTKCEIMCDKMTSRIPVALLIRYQLNQESCGK 60 Rat MAPSQLAWLLRLAAFFHLCTLLAGQHLGMTKCNITCHKMTSPIPVTLLIHYQLNQESCGK 60 Monkey MAPISLSWLLHLATLCHLTVLLAGQHHGVTKCNITCSKMTSKIPVALLIHYQQNQESCGK 60

Chicken KAIIFTTKRNREICANPYEPWVEKIVKKLDQEKASAASPLPRADTSPAAAVPKEPGIFQK 119 Human RAIILETRQHRLFCADPKEQWVKDAMQHLDR------------OAAALTRNGGTFEK 105 Mouse RAIVLETTQHRRFCADPKEKWVQDAMKHLDH---------------QAAALTKNGGKFEK 105 Rat RAIILETRQHRHFCADPKEKWVQDAMKHLDH--------------QTAALTRNGGKFEK 105 Monkey RAIVLETRQHRLFCADPKEQWVKDAMQHLDR------------QAAALTRNGGTFEK 105

Chicken HTGLQVPPSPPATAATAASERAPTPAASTEATSKPSPAMONATHFSAGPSAVTSGVATHS 179 Human QIGEVKPRTTPAAGGMDESVVLEPE-ATGESSSLEPTPSSQEAQRALGTSPELPTGVTG- 163 Mouse RVDNVTPGITLATRGLSPSALTKPESATLEDLALELTTISQEARGTMGTSQEPPAAVTG- 164 Rat RVDNVTPRITSTTRGLSPTALAKPESATVEDLTLEPTAISQEARRPMGTSQEPPAAVTG- 164 Monkey QVGLVKPRTTLAARGMEESAVPEPE-ATGESSSLKPTPSSREAQTALGTSPEQSTGVTG- 163

Chicken EVVSEANRESLTSAHSTADAVDMALGQRTSYPTAPARDSDSKEEPAGYATSAAGDVRGTT 239 Human ---SSGTRLPPTPKAQDGGPVGTELFRVPPVSTAATWQSSAPHOPG---PSLWAEAKTSE 217 Mouse ---SSLSTSEAQDAGLTAKPQSIGSFEAADISTT-VWPSPAVYQSG---SSSWAEEKATE 217 Rat ---SFPSTSKAQDAGLAAKPQSTGISEVAAVSTT-IWPSSAVYQSG---SSLWAEEKATE 217 Monkey ---SSGTGLPLTPKAQDGGPVGTELFRGPPVSTAAAWQSSAPHQPG---PGLWAEGKTSE 217

Chicken STSTSDPASIS------KGLDHPSLPTNVPLDTISARGSTSGTALRSSALPSTPHITEVG 293 Human APSTQDP----------STQASTASSPAPEENAPSEGQRVWGQGQSPRPENSLEREEMG 266 Mouse SPSTTAP----------SPQVSTTSPSTPEENVGSEGQPPWVQGQDLSPEKSLGSEEIN 266 Rat SPPTIAL-_--_-----STQVSTTS--SPKQNVGSEGQPPWVQEQDSTPEKSPGPEETN 264 Monkey APSTQDPSTQASSNPRASSTQASTTSSPAPEENTPSEGQPVWGQGQSPRPENSLEREEMG 277

Chicken MVPSTPQASPSPTQNPTTAIDEGPYVHANKNFSSSAFGTGTLDHLLPSGKQGPLDMLVFT 353 Human PVPAHTDAFQ--------DWGPGSMAHVSVVPVSSEGTPSREPVASGSWTPKAEEPIH 316 Mouse --PVHTDNFQ--------ERGPGNTVHPSVAPISSEETPSPELVASGSQAPKIEEPIH 314 Rat --PVHTDIFQ---------DRGPGSTVHPSVAPTSSEKTPSPELVASGSQAPKVEEPIH 312 Monkey PVPAHTDAFQ--------DWGPGSMAHVSVVPVSSEGTPSREPVVSGSWTPKAEEPIH 327

Chicken SQIFSDQARAQATGSPSHPPALSSLSGSQMYLVIPVALIGVLIACGVAARWAYVKFEIRP 413 Human ATMDPQRLGVLITPVP-----DAQAATRRQAVGLLAFLGLLFCLGVAM-FTYQSLQGCP 369 Mouse ATADPQKLSVLITPVP-----DTQAATRRQAVGLLAFLGLLFCLGVAM-FAYQSLQGCP 367 Rat ATADPQKLSVFITPVP-----DSQAATRRQAVGLLAFLGLLFCLGVAM-FAYQSLQGCP 365 Monkey ATMDPQRLGVLITPVP-----DSQAATRRQAVGLLAFLGLLFCLGVAM-FAYQSLQGCP 380
\end{abstract}

Chicken ETTSREMVEALLYLKEGHRDNVYPMEVI 441

Human RKMAGEMAEGLRYIPRSCGSNSYVLVPV 397

Mouse RKMAGEMVEGLRYVPRSCGSNSYVLVPV 395

Rat RKMAGEMVEGLRYVPRSCGSNSYVLVPV 393

Monkey RKMAGEMVEGLRYIPRSCGSNSYVLVPV 408

Figure 3

Alignment of amino acid sequences of chicken, human, mouse, rat and monkey chemokine $\mathrm{CX}_{3} \mathrm{CLI}$. Alignment gaps are indicated by dashes. Sequences identical in all species are highlighted in gray. The asterisk represents the conserved cysteine residues. 
Table I: Chicken and corresponding human chemokine cysteine motifs

\begin{tabular}{|c|c|c|c|}
\hline Families & Chemokines & Chicken motif & Human motif \\
\hline \multirow[t]{9}{*}{$\mathrm{CC}$} & CCLILI & $\mathrm{CCX}_{25} \mathrm{CX}_{15} \mathrm{C}$ & $\mathrm{CCX}_{22} \mathrm{CX}_{15} \mathrm{C}$ \\
\hline & CCLIL2 & $\mathrm{CCX}_{24} \mathrm{CX}_{15} \mathrm{C}$ & $\mathrm{CCX}_{22} \mathrm{CX}_{15} \mathrm{C}$ \\
\hline & CCL3LI, CCL4LI, CCL5 & $\mathrm{CCX}_{22} \mathrm{CX}_{15} \mathrm{C}$ & $\mathrm{CCX}_{22} \mathrm{CX}_{15} \mathrm{C}$ \\
\hline & CCLI6 & $\mathrm{CCX}_{22} \mathrm{CX}_{15} \mathrm{C}$ & $\mathrm{CCX}_{21} \mathrm{CX}_{15} \mathrm{C}$ \\
\hline & CCLI7 & $\mathrm{CCX}_{22} \mathrm{CX}_{15} \mathrm{C}$ & $\mathrm{CCX}_{22} \mathrm{CX}_{15} \mathrm{C}$ \\
\hline & CCLI9 & $\mathrm{CCX}_{25} \mathrm{CX}_{15} \mathrm{C}$ & $\mathrm{CCX}_{24} \mathrm{CX}_{15} \mathrm{C}$ \\
\hline & CCL20 & $\mathrm{CCX}_{24} \mathrm{CX}_{15} \mathrm{C}$ & $\mathrm{CCX}_{24} \mathrm{CX}_{15} \mathrm{C}$ \\
\hline & CCL2I & $\mathrm{CCX}_{25} \mathrm{CX}_{15} \mathrm{C}$ & $\mathrm{CCX}_{24} \mathrm{CX}_{17} \mathrm{C}$ \\
\hline & CCL/MCP-LI, -L2, -L3 & $\mathrm{CCX}_{22} \mathrm{CX}_{15} \mathrm{C}$ & $\mathrm{CCX}_{22} \mathrm{CX}_{15} \mathrm{C}$ \\
\hline \multirow[t]{5}{*}{$\mathrm{CXC}$} & CXCL8a, CXCL8b & $\mathrm{CXCX}_{24} \mathrm{CX}_{15} \mathrm{C}$ & $\mathrm{CXCX}_{24} \mathrm{CX}_{15} \mathrm{C}$ \\
\hline & CXCLI3a, CXCLI3b, CXCLI3c & $\mathrm{CXCX}_{24} \mathrm{CX}_{15} \mathrm{C}$ & $\mathrm{CXCX}_{24} \mathrm{CX}_{15} \mathrm{C}$ \\
\hline & $\mathrm{CXCLI} 2$ & $\mathrm{CXCX}_{22} \mathrm{CX}_{15} \mathrm{C}$ & $\mathrm{CXCX}_{22} \mathrm{CX}_{15} \mathrm{C}$ \\
\hline & CXCLI4 & $\mathrm{CXCX}_{23} \mathrm{CX}_{19} \mathrm{C}$ & $\mathrm{CXCX}_{23} \mathrm{CX}_{20} \mathrm{C}$ \\
\hline & CXCLI5 & $\mathrm{CXCX}_{24} \mathrm{CX}_{15} \mathrm{C}$ & N/A 1 \\
\hline XC & XCLI & $\mathrm{CX}_{36} \mathrm{C}$ & $\mathrm{CX}_{36} \mathrm{C}$ \\
\hline $\mathrm{CX}_{3} \mathrm{C}$ & $\mathrm{CX}_{3} \mathrm{CLI}$ & $\mathrm{CX}_{3} \mathrm{CX}_{21} \mathrm{CX}_{15} \mathrm{C}$ & $\mathrm{CX}_{3} \mathrm{CX}_{21} \mathrm{CX}_{15} \mathrm{C}$ \\
\hline
\end{tabular}

I CXCLI5 is not found in humans.

\section{Chromosomal locations and syntenies}

Comparisons of the chromosomal segments containing chemokines in the human, mouse, and chicken indicate that the organization of the chemokine genes was generally conserved between chickens and mammals (Figure 5 and 6). Chicken CC and CXC chemokines are located on Chromosomes 1, 4, 6, 9, 13, 19, and Z. Like human and mouse, there are two large clusters in the chicken genome, located on Chromosome 19 and containing 9 CCL genes. Two CCL1-like (CCL1L1 and 2) and three chicken MCPlike (CCL/MCP-L1, L2, and L3) genes related to human and mouse MCPs, such as CCL2, 7, 8, 11, and 13, are in one cluster (Figure 5A), and CCL5, CCL16, CCL3L1, and CCL4L1 genes in another cluster (Figure 5B). Another CCL cluster is located on Chromosome $\mathrm{Z}$ containing two genes, CCL19 and CCL21 (Figure 5C). Two CXCL gene clusters are located on Chromosome 4 and contained 6 genes, two CXCL8 (CXCL8a and b) and one CXCL15 genes in one cluster (Figure 6A) and three CXCL13 (CXCL13a, b, and c) genes in another (Figure 6B). Chicken shares the syntenies with mouse and human in all these regions. There is one composite cluster containing one $\mathrm{CX}_{3} \mathrm{CL} 1$ and one CCL17 genes (Figure 6E). Synteny was conserved in chicken on one side of this cluster. Chicken CCL20, CXCL12, CXCL14, and XCL1 are individually located on Chromosomes 9 (Figure 5D), 6 (Figure 6C), 13 (Figure 6D), and 1 (Figure 6F), respectively, and the syntenies were highly conserved between chicken, mouse, and human in these four locations. Mammalian CCL25, CCL28, and CXCL16 were not found in the chicken genome, although the syntenies associated with CCL25 and CCL28 were also conserved in chickens. A number of human chemokines including CCL2, 7, 8, 11,
15, 18, 23, 24, and 26, CXCL1, 2, 3, 4, 5, 6, 7, 9, 10, and 11 in chemokine clusters that share syntenies with chicken clusters on Chromosome 4, and 19 were not found in the chicken genome, indicating gene duplications in mammals.

Chemokine receptor genes were also highly conserved between chicken, human, and mouse, and were similarly clustered. The largest cluster of chicken chemokine receptors was found on Chromosome 2, where 5 receptor genes (CCR2, CCR5, CCR8L1, CCR9, and XCR1) were identified. Another cluster on Chromosome 2 contains CCR4, CCR8, and $\mathrm{CX}_{3} \mathrm{CR} 1$ genes. Chicken CXCR1 and CXCR2 are also clustered as in mammals, but the chromosomal segment is unknown. The remaining CCR and CXCR genes are individually located on Chromosomes 3 (CCR6), 27 (CCR7), 7 (CXCR4), and 24 (CXCR5). Several human chemokine receptors, such as CCR1, CCR3, CCR10, CXCR3, and CXCR6 were not found in the chicken genome, though the syntenies associated with these receptors are present in the chicken genome.

\section{Gene structure}

According to the chicken genome sequence, chicken chemokine genes share typical three-exon CC and fourexon CXC gene structures with mammals except for CXCL13a and CXCL13b, which have only three exons. Chicken chemokine genes are shorter than the corresponding human genes due to shorter introns in chickens. The gene structure of chemokine receptors was also conserved between chicken and mammals. The EST sequences indicate that chicken chemokine receptor genes could have up to 5 exons, though the complete sequences 


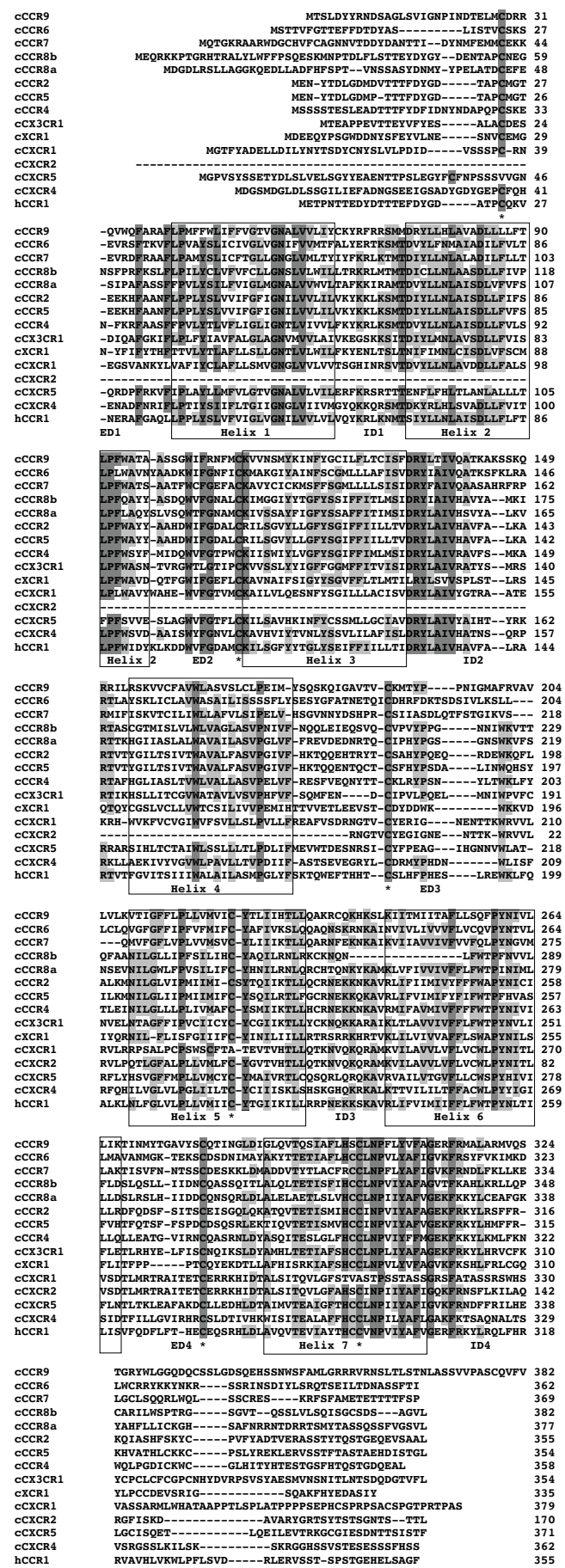

\section{Figure 4}

Alignment of amino acid sequences of chicken chemokine receptors with human CCRI. Alignment gaps are indicated by dashes. Sequences with identical amino acid in at least $50 \%$ or $85 \%$ of the chicken chemokines are highlighted in gray and dark gray, respectively. Asterisks represent the conserved cysteine residues. ED and ID denote extracellular and intracellular domains, respectively. Seven transmembrane spanning domains of chicken chemokine receptors were predicted using the SMART program and these consensus domains are indicated with a box. The N-terminal sequence of chicken CXCR2 is currently unknown. 


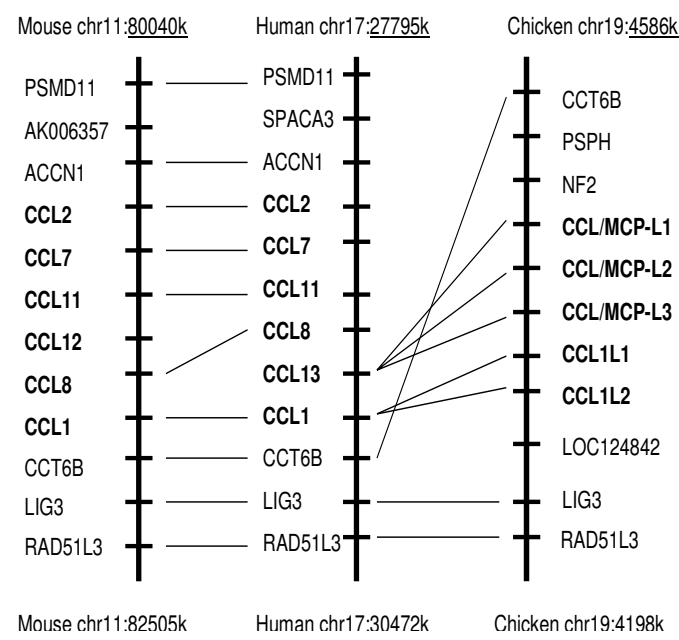

A

Mouse chr4:41805k Human chr9:34603k Chicken chr7 random:7421k

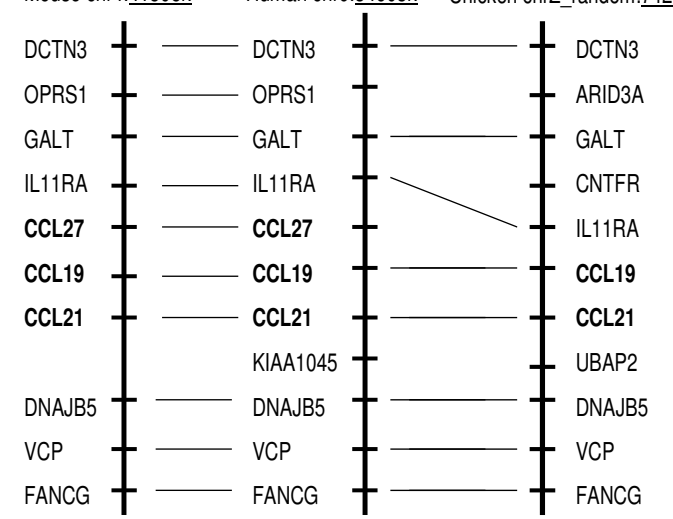

Mouse chr4:42256k Human chr9:35071k Chicken chrZ_random:7974k

C

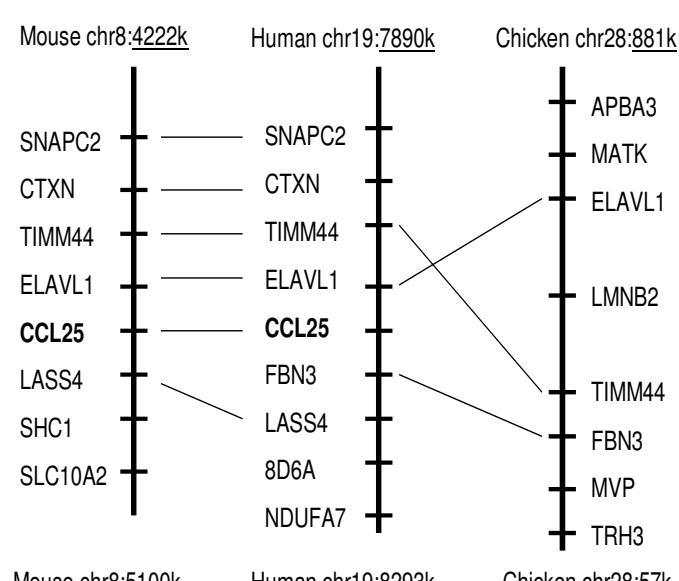

Mouse chr8:5100k Human chr19:8293k Chicken chr28:57k

$\mathbf{E}$

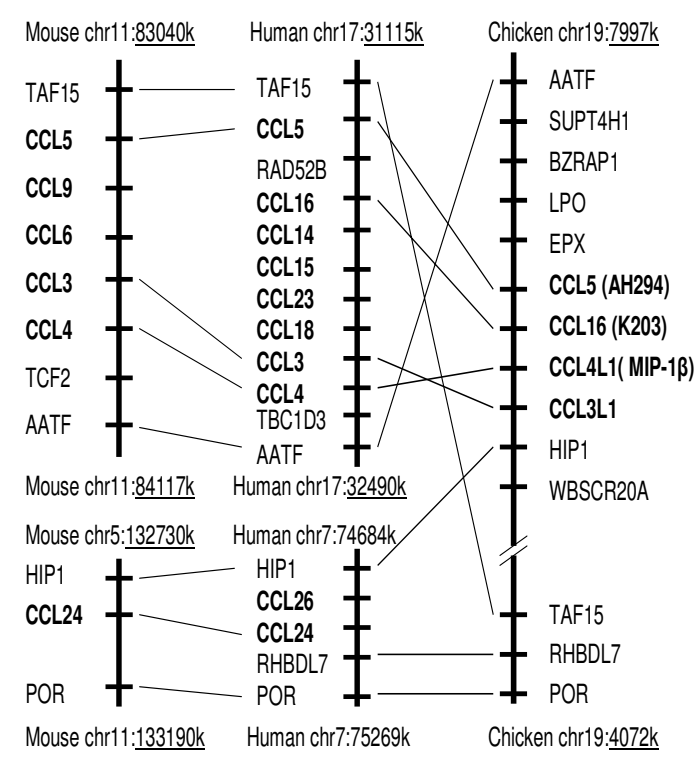

B

Mouse chr1:83360k Human chr2:228160k Chicken chr9:4180k

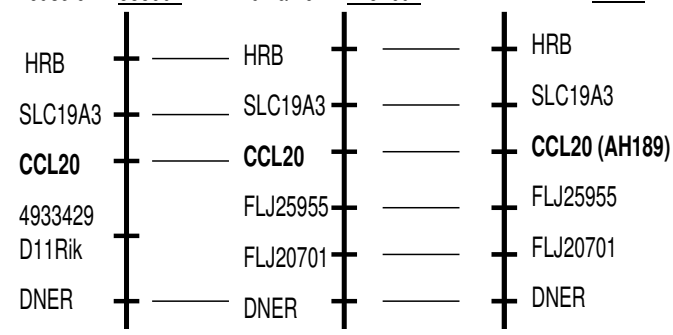

Mouse chr1:85225k Human chr2:230430k Chicken chr9:3650k

D

Mouse chrUn_random:20703k Human chr5:42835k Chicken chrZ:6659k

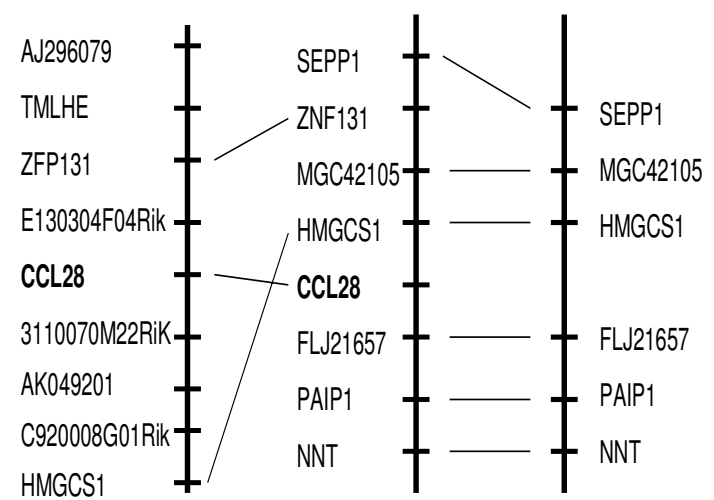

Mouse chrUn_random:23586k Human chr5:43750k Chicken chrZ:6856k F

\section{Figure 5}

Genomic organization (syntenies) of human, mouse, and chicken CCLs, CX3CLs, and XCLs 


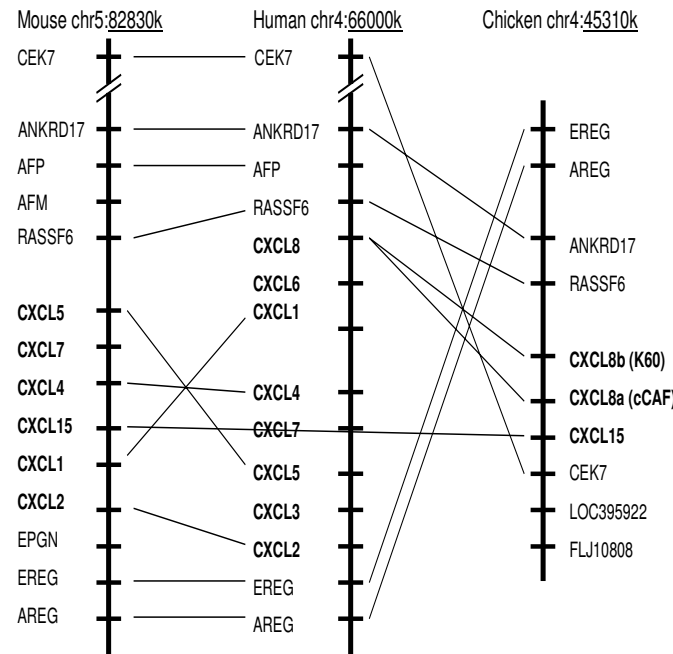

Mouse chr5:

A

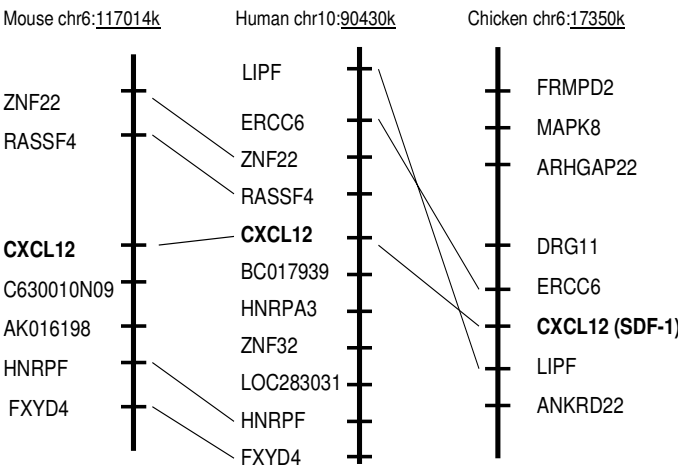

Mouse chr6:118327k Human chr10:43186k Chicken chr6: $18345 \mathrm{k}$

C

Mouse chr8:93875k Human chr16:55680k Chicken chr11:504k

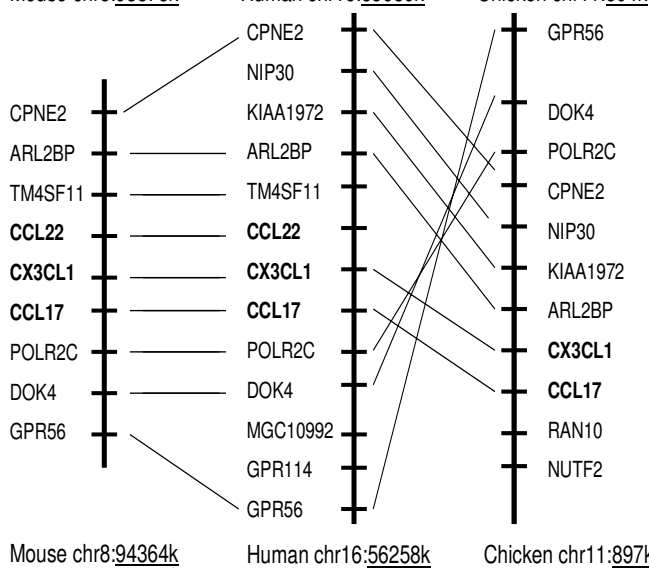

E

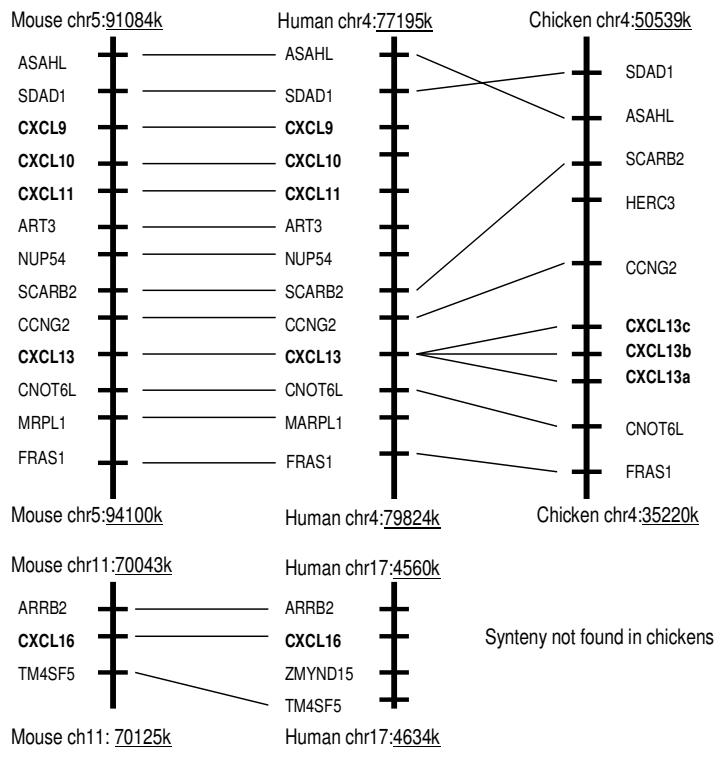

B

Mouse chr13:54922k Human chr5:134390k Chicken chr13:14547k

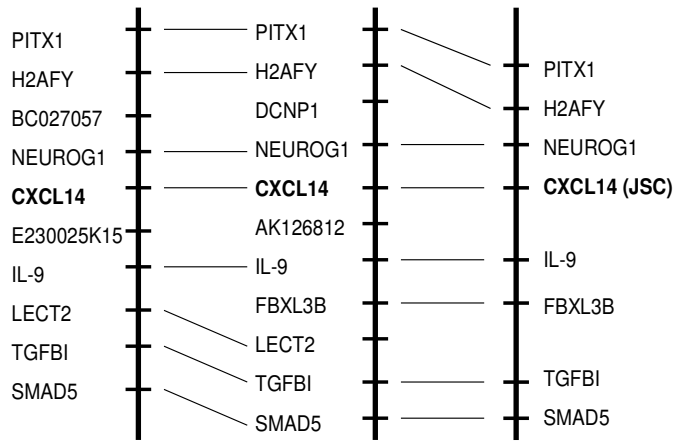

Mouse chr13:55850k Human chr5:135550k Chicken chr13:13974k

D

Mouse chr1:165481k Human chr1:164838k Chicken chr1:

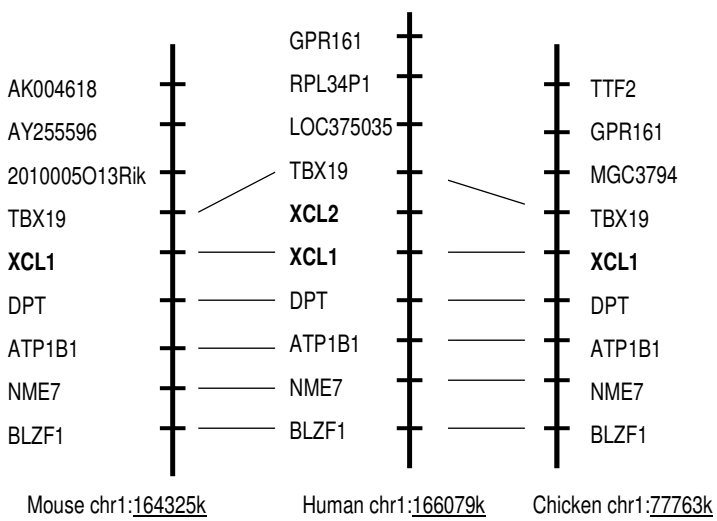

F

Figure 6

Genomic organization (syntenies) of human, mouse, and chicken CXCLs 
were not available. However, the expressed sequences show that the amino acid sequences of identified chicken receptors are mostly encoded in a single exon as are most of the mammalian chemokine receptors. Chicken ESTs aligned with the chicken genome sequence indicate that these receptor mRNAs have approximately $2 \mathrm{~kb}$ of 5 ' UTR, as do those found in humans.

\section{Phylogenetic analyses and nomenclatures}

The phylogenetic trees (Figure $7 \mathrm{~A}, 7 \mathrm{~B}$, and 8 ) show that chicken CCL5, 16, 17, 19, and 20 and all seven CXCLs are closely related to single specific human and/or mouse chemokines. The phylogenetic trees together with the syntenies associated with these genes (Figure 5 and 6) strongly indicate that these genes are the orthologs of those found in mammals; therefore, they are named accordingly. The phylogenetic results show that chickens have two CXCL8 and three CXCL13 genes (only one copy each in mammals), indicating gene duplications of these genes in aves. One chicken CXCL related to mouse CXCL15 but not to human CCLs is named as CCXCL15, which is also supported by the synteny of the chemokine cluster (Figure 6A). Chicken CCL21 is named according to relatedness to the human and mouse and the highly conserved synteny (Figure 5C). According to the phylogenetic tree in Figure 7B, two directly linked chicken CCLs are remotely related to human and mouse CCL1. The synteny associated with these genes also indicates that they may be CCL1-like genes (Figure 5A); therefore, they are named as CCL1L1 and CCL1L2. Three closely related chicken CCLs that are directly linked to the CCL1-like genes are related to a group of clustered human and mouse MCP CCLs (2, $7,8,11$, and 13) in the phylogenetic tree. The synteny and phylogenetic tree do not provide information to a specific mammalian ortholog, though these three chicken genes are somewhat more similar to human CCL13 and mouse CCL2. The results indicate that these genes are chicken MCP-like (Figure 5A and 7B); therefore, they are named as CCL/MCP-like (CCL/MCP-L1, -L2, and -L3). A chicken CCL gene that is directly linked to CCL16 and CCL5 (Figure $5 \mathrm{~B}$ ) is distantly related to chicken CCL5 in the tree. This gene has been reported as MIP-1 $\beta$-like chemokine [13], which is CCL4 in humans and mouse. Therefore, it is named as CCL4L1 in order to conform to the report. Another CCL in this cluster that does not display relatedness to other CCLs in the phylogenetic tree (Figure 7B) is named as CCL3L1 because this chemokine displays highest sequence similarity to a human CCL3-like chemokine, and it shares synteny with human CCL3 genes (Figure 5B). Overall, CXCLs are more conservative among chicken, human, and mouse than CCLs.

Chicken chemokine receptors can also be named according to mammalian nomenclature based on phylogenetic analysis (Figure 7) and syntenies. The genetic distances appear to be shorter between chicken and mammalian chemokine receptors than those between chicken and mammalian chemokines, which probably due to highly conserved transmembrane domains in these receptors. Chicken CCR4, CCR6, CCR7, CCR9, CXCR2, CXCR4, CXCR5, CX3CR1, and XCR1 are closely related to a mammalian ortholog based on the phylogenetic analysis. There are two distantly related (relative to the distance between mouse and human CCR8) CCR8 genes in chickens. The one closer to human CCR8 is named as CCR8a and the other as CCR8b. There are also two chicken CCRs closely related to human and mouse CCR2 and CCR5, but the phylogenetic analysis could not distinguish them as either CCR2 or CCR5. Because these two receptors are located in a conserved chromosomal region on chicken, human, and mouse chromosomes, these two chicken CCRs were named as CCR2 and CCR5 based on the synteny in which CCR2 is closer to XCR1 than CCR5.

In summary, 23 chemokine and 14 chemokine receptor genes were identified from the chicken genome in this study. Many chicken genes display high degrees of similarity with their human and mouse orthologs in terms of gene structure, sequence homology, and synteny. Chicken has significantly fewer CCLs, CXCLs, CCRs, and CXCRs than mammals, but it has the same number of $\mathrm{CX}_{3} \mathrm{C}, \mathrm{XC}$, and cognate receptors as mouse. The results of phylogenetic analyses generally agree with the comparative chromosomal locations and syntenies of the genes. The independent nomenclature of chicken chemokines and chemokine receptors suggests that the chicken may have ligand-receptor pairings similar to mammals. The organization of these genes suggests that there were a substantial number of these genes present before divergence between aves and mammals and more gene duplications of $\mathrm{CC}$, CXC, CCR, and CXCR subfamilies in mammals than in aves after the divergence.

\section{Discussion}

We systematically searched for chicken chemokine and chemokine receptor genes in the recently available draft chicken genome sequence. Without this information, it may have taken years to find chicken chemokines and their receptors. The independent nomenclature of chicken chemokines and chemokine receptors and mammalian chemokine-receptor binding information suggest that most of the genes have been identified. One exception was CCL25, the only known ligand of CCR9 in mammals, which was not found in this study though its receptor was identified. Likewise, CXCL14, and CXCL15 were identified in both chickens and mice, but their receptors are unknown; therefore, it is very likely that there are additional chicken chemokine and chemokine receptor genes in the chicken genome. 


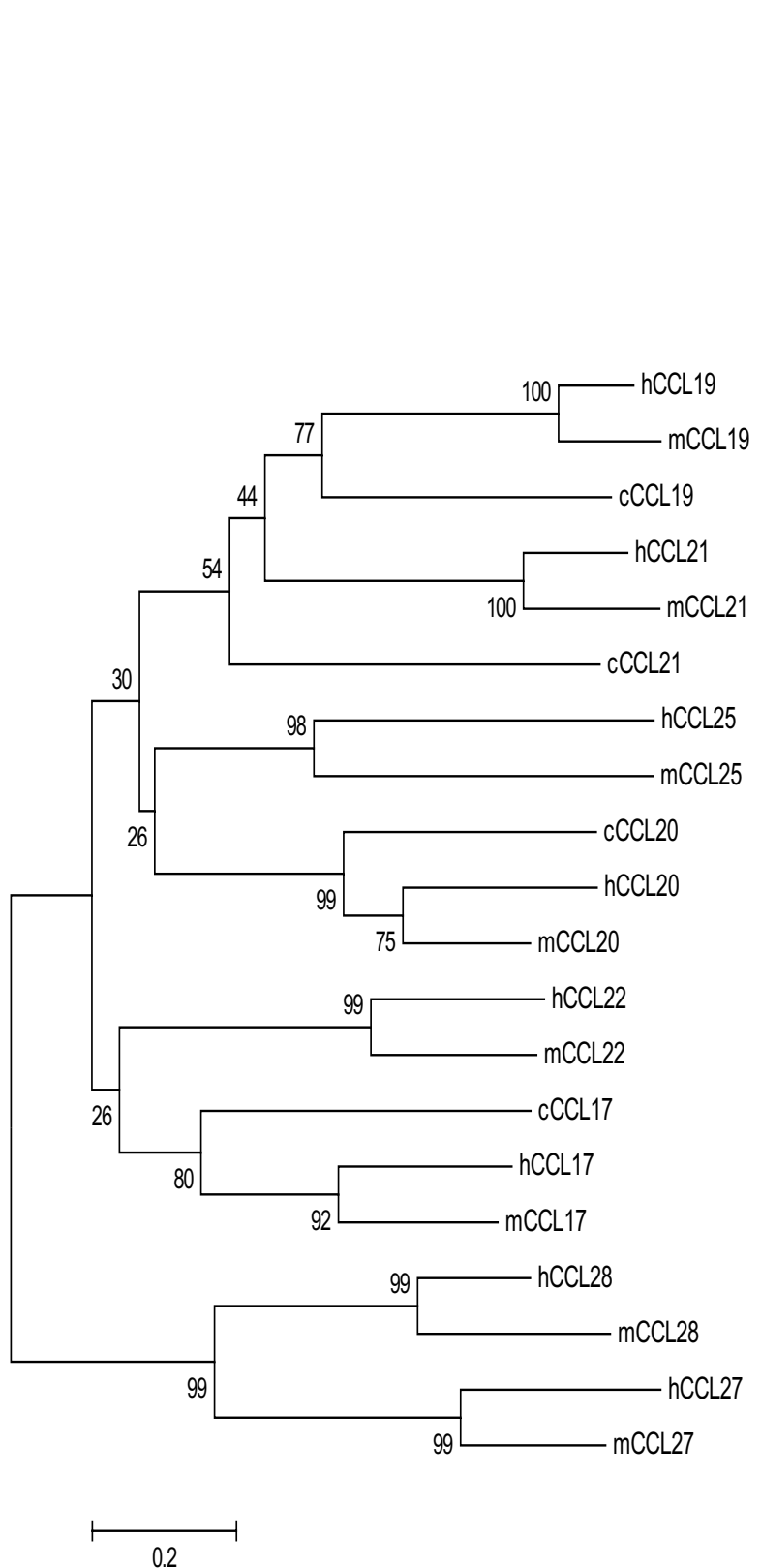

A

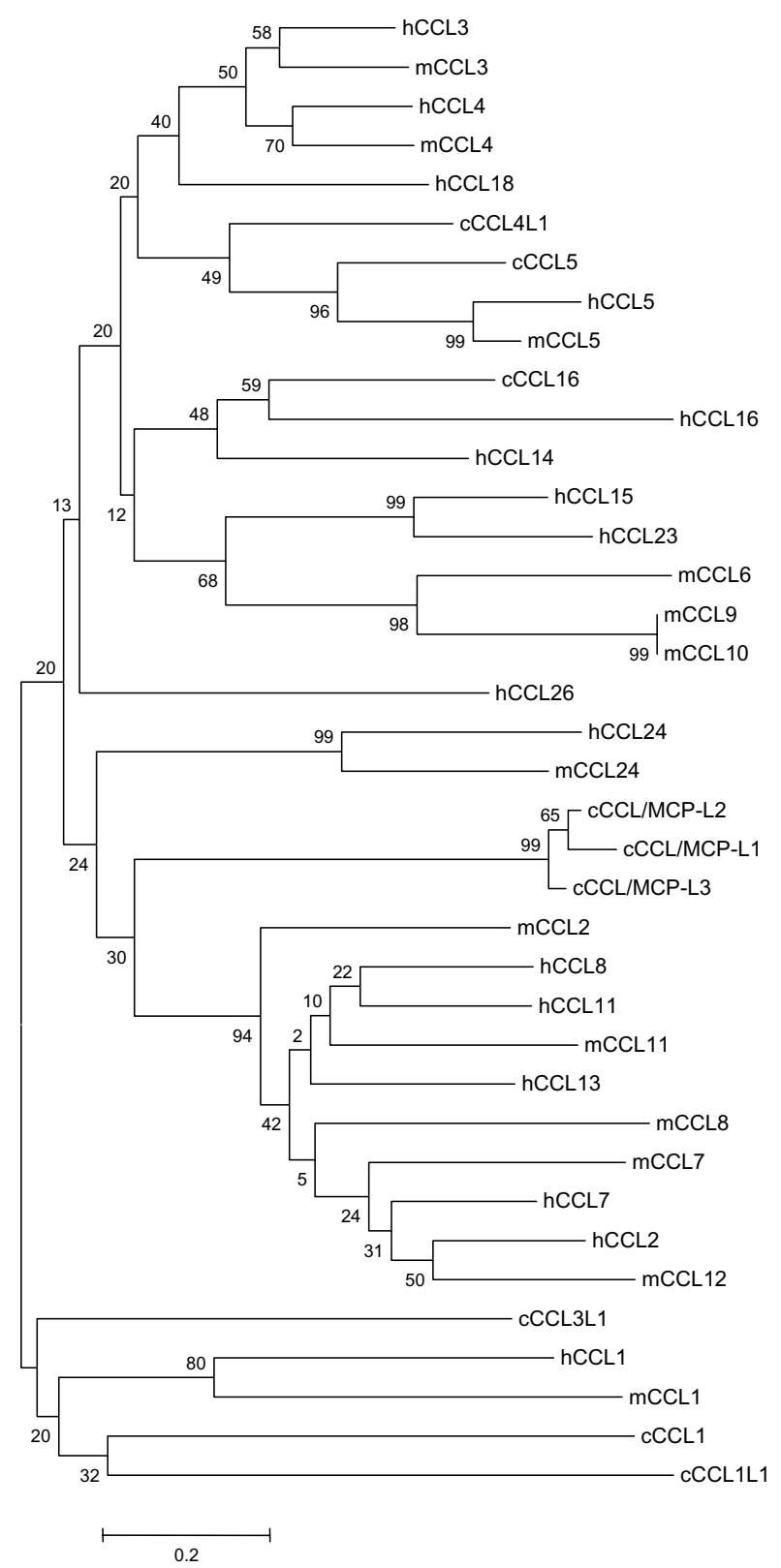

B

\section{Figure 7}

Phylogenetic trees of the chemokine CC subfamily constructed using the amino acid sequences of chicken, human, and mouse chemokines. The numbers on the branches are bootstrap values (percentage that the simulation supports the original interpretation). Human, mouse, and chicken are abbreviated as $\mathrm{h}$, $\mathrm{m}$, and $\mathrm{c}$, respectively. The scale bar reflects the horizontal distance at which amino acid sequences differ by $20 \%$ between two sequences. $A$ and $B$ are the phylogenetic trees of CCLs that are not located on Chromosome 19 or located on Chromosome 19, respectively. 


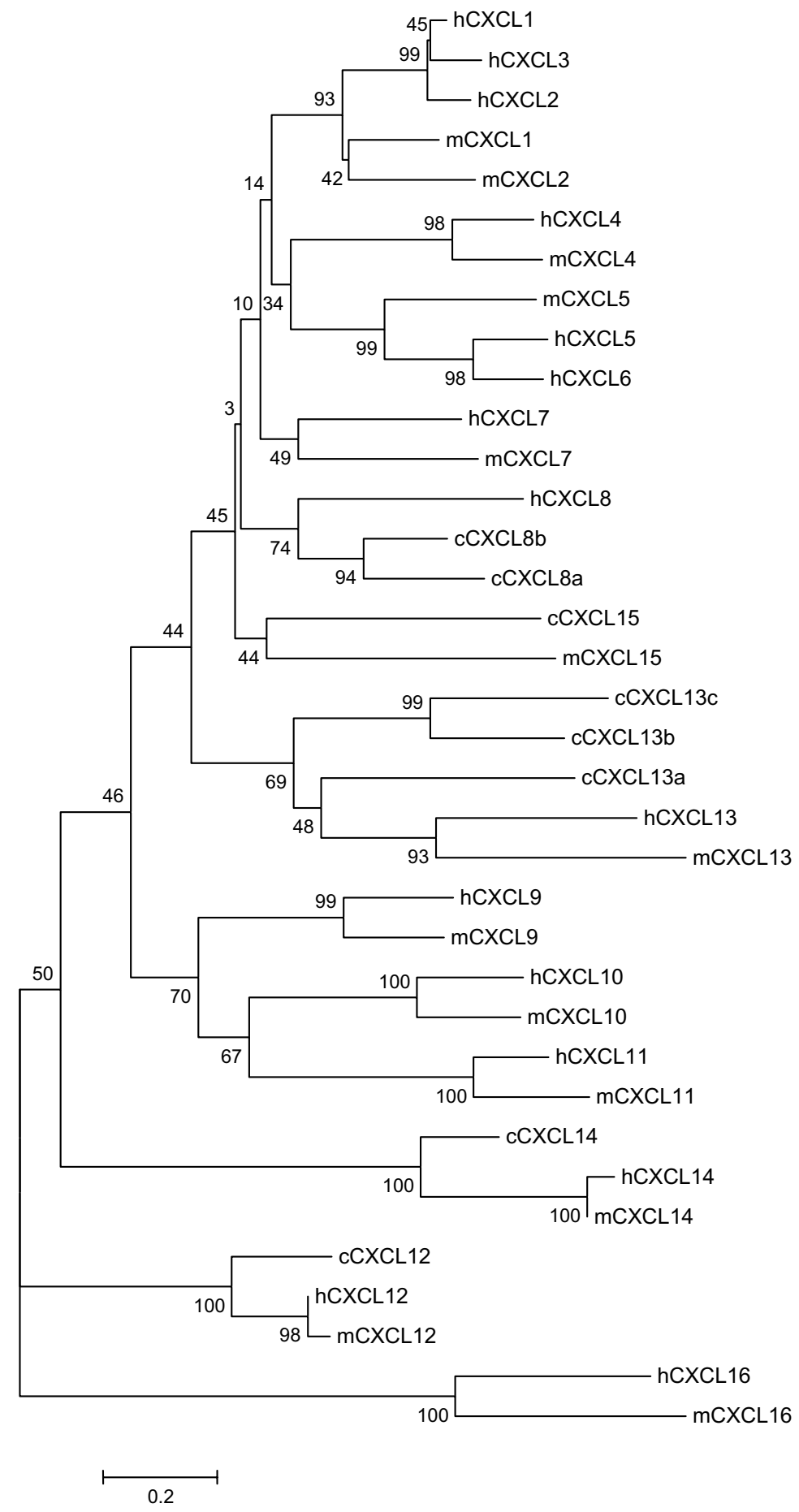

Figure 8

Phylogenetic tree of the chemokine CXC subfamily constructed using the amino acid sequences of chicken, human, and mouse chemokines. The numbers on the branches are bootstrap values (percentage that the simulation supports the original interpretation). Human, mouse, and chicken are abbreviated as $\mathrm{h}, \mathrm{m}$, and $\mathrm{c}$, respectively. The scale bar reflects the horizontal distance at which amino acid sequences differ by $20 \%$ between two sequences. 
Although most of the systematic nomenclature of the chicken genes was unambiguous based on both phylogenetic trees and syntenies, the information that was used to name seven chicken CCLs as CCL1L1, CCL1L2, CCL3L1, CCL4L1, CCL/MCP-L1, CCL/MCP-L2, and CCL/MCP-L3 and to distinguish two chicken chemokine receptors into CCR2 and CCR5 is inadequate. CCR2 and CCR5 are closely related and tightly linked in the human, mouse, and chicken genomes. The phylogenetic analysis indicates these genes were duplicated after the divergence between mammals and aves. Chicken CCL/MCP-L1, -L2, and -L3 were related to a group of clustered mouse and human MCP CCLs; therefore, specific cognate receptors must be tested to distinguish them. In humans, the chemokines of this MCP group and MIPs, such as CCL3, CCL4, and CCL5, can bind to more than one receptor, such as CCR1, 2, 3, and/or 5, but not both CCR2 and CCR5. CCR1 and CCR3 were not found in the chicken genome and probably are not present in the species. Therefore, chicken CCR2 and CCR5 may be two receptors that recognize these two groups of CCL chemokines, such as CCR2 for MCPs and CCR5 for MIPs. Interestingly, two CCL1 like (CCL1L1 and CCL1L2) and two CCL1 receptor (CCR8a and CCR8b) genes were found in the chicken genome. The ligand-receptor binding for these four genes can not be determined in this study. Nerveless, the names assigned based on comparative analysis in this study may prove useful in order to apply the functional and physiological knowledge from other species to chickens. Further lab testing must be carried out to confirm the ligand-receptor binding and to understand their biological functions.

Chicken chemokine ESTs are highly represented in the EST database. There are several ESTs aligned to each identified chicken chemokine gene in the UCSC Genome browser. The sequences assembled from ESTs probably contained most, if not all, of the full-length chemokine mRNA sequences. Promoter sequences with a typical TATAA were detected with promoter prediction software (data not shown). However, there were only a few ESTs that partially cover chicken chemokine receptor genes. Some of these EST contain translation start sites. These EST sequences and reported complete coding sequences indicate that the amino acid sequences of chicken chemokine receptors are mostly encoded in one exon. The predicted amino acid sequences were of the expected length and aligned very well with the coding sequences of nonchicken reference genes in the UCSC genome browser. The conserved gene structure of this receptor family and high sequence similarity between chicken and mammals suggest that the predicted coding sequences were very accurate, especially for those with ESTs containing translation start sites. CCR4 is the only predicted gene that does not have a matching EST and CXCR2 is the only identified gene with partial sequence. Further study including sequencing expressed sequences is needed to confirm these genes.

\section{Conclusion}

Based on the organization, syntenies, and phylogenetic trees of chicken, mouse, and human chemokine and chemokine receptor genes, we conclude that there may be a substantial number of chemokine and cognate receptor genes before divergence between aves and mammals. The presence of a few chicken chemokine and chemokine receptor paralogs and orthologs of the mammalian genes indicated that most chicken chemokine and the receptor genes shared common ancestors with the human and mouse genes. There were significantly more gene duplications of CC, CXC, CCR, and CXCR subfamilies in mammals than in aves after the divergence of mammals and aves. The mammalian and chicken genome sequences and the genes identified in this study can be used for further investigation of the molecular evolution of these gene families and as a model for the study of the divergence between aves and mammals. Avian and mammalian species may share similar chemokine-receptor binding patterns. The results of this study may be used as functional inferences for these chicken genes before they are experimentally tested.

\section{Methods \\ Gene identification}

To identify syntenies, genes closely linked to human and mouse chemokines were identified and localized on the chicken genome using the UCSC genome browser [25]. Expressed Sequence Tags (ESTs) and chicken mRNA sequences in the corresponding chromosomal regions were then identified and, if necessary, assembled with the CAP3 program $[26,27]$. These sequences were aligned with the corresponding chicken genomic sequence and any deletions or insertions corrected. Sequences were then submitted to ORF Finder (Open Reading Frame Finder) [28] and the open reading frames were used as queries in BLASTP $[29,30]$ searches against the non-redundant protein database in Genbank [31]. Sequences that produced significant alignments with chemokines were identified as putative chicken chemokine sequences. To identify chicken chemokine receptors, all sequences of putative chicken chemokine receptors including ESTs, mRNAs, and predicted sequences were retrieved from the UCSC Genome Browser. The identified ESTs were used to determine the translation start sites for the receptors. If the translation start sites could not be determined from ESTs, translation start sites were based on the most likely predicted sequences from non-chicken reference genes in the UCSC Genome Browser. 


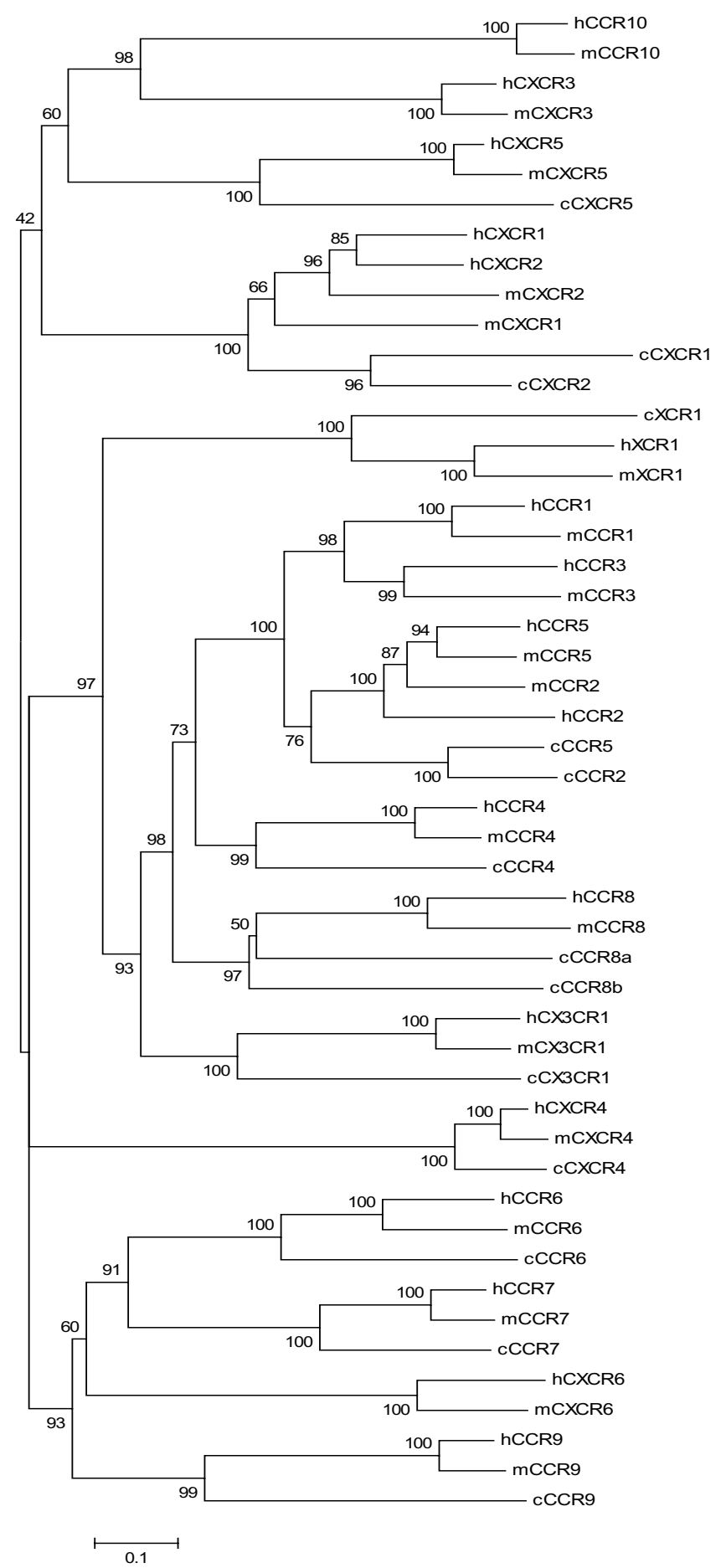

Figure 9

Phylogenetic tree of chemokine receptors constructed using the amino acid sequences of chicken, human, and mouse chemokine receptors. The numbers on the branches are bootstrap values (percentage that the simulation supports the original interpretation). Human, mouse, and chicken chemokines are abbreviated as $\mathrm{h}, \mathrm{m}$, and $\mathrm{c}$, respectively, followed by the receptor named. The scale bar reflects the horizontal distance at which amino acid sequences differ by $10 \%$ between two sequences. 


\section{Sequence analyses}

Complete amino acid sequences of currently known human and mouse chemokines were retrieved from Genbank. The amino acid sequences of all putative chicken chemokines were predicted based on the open reading frames of the expressed nucleotide sequences (ESTs or mRNAs). The amino acid sequences were grouped according to $\mathrm{CC}, \mathrm{CXC}$, and $\mathrm{CX}_{3} \mathrm{C}$ motifs and aligned using the ClustalW program $[32,33]$. The similarity of the amino acid sequences was determined based on alignments with the most likely human or mouse orthologs. Human CCR1 was included in the multiple alignments of chicken chemokine receptors for comparison. The seven transmembrane domains were predicted using the SMART program [34].

For comparison, human chemokines hCCL1 (GenBank accession number: (NM_002981), hCCL2 (BC009716), hCCL3 (BC071834), hCCL4 (NM_002984), hCCL5 (BC008600), hCCL7 (NM_006273), hCCL8 (NM_005623), hCCL11 (BC017850), hCCL13 (BC008621), hCCL14(BC045165), hCCL15 (NM_032964), hCCL16 (NM_004590), hCCL17 (BC069107), hCCL18 (BC069700), hCCL19 (BC027968), hCCL20 (BC020698), hCCL21 (BC027918), hCCL22 (BC027952), hCCL23 (NM_145898), hCCL24 (BC069072), hCCL25 (NM_005624), hCCL26 (BC069394), hCCL27 (AJ243542), hCCL28 (AF220210), hCXCL1 (BC011976), hCXCL2 (BC015753), hCXCL3 (BC065743), hCXCL4 (NM_002619), hCXCL5 (BC008376), hCXCL6 (BC013744), hCXCL7 (BC028217), hCXCL8 (BC013615), hCXCL9 (BC063122), hCXCL10 (BC010954), hCXCL11 (BC012532), hCXCL12 (BC039893), hCXCL13 (BC012589), hCXCL14 (BC003513), and hCXCL16 (BC017588), and hCX ${ }_{3}$ CL1(NM_002996) and mouse chemokines CCL1 (NM_011329), mCCL2 (NM_011333), mCCL3 (NM_011337), mCCL4 (NM_013652), mCCL5 (BC033508), mCCL6 (BC002073), mCCL7 (BC061126), mCCL8 (NM_021443), mCCL9 (NM_011338), mCCL10 (U15209), mCCL11 (NM_011330), mCCL12 (BC027520), mCCL17 (BC028505), mCCL19 (BC051472), mCCL20 (BC028504 (NM_009138), mCCL27 (BC028511), mCCL28 (BC055864), and $\mathrm{mCX}_{3} \mathrm{CL} 1$ (BC054838) were retrieved from the GenBank. Reported chicken chemokines K60 (Y14971), cCAF (M16199), MIP-1ß (AJ243034), k203 (Y18692), AH294 (AY037859), AH221 (AY037860), AH189 (AY037861), JSC (AF285876), SDF-1(BX936268), Clone 391 (L34552) and lymphotactin (AF006742) are included in this study. Rat (BC070938) and monkey (AF449286) CX CL1 were $_{3}$ also retrieved for $\mathrm{CX}_{3} \mathrm{CL}$ sequence analysis. There are several human chemokine-like genes in the human genome, which were not included in this study.
Human and mouse chemokine receptors hCCR1 (NM_001295), hCCR2 (NM_000647), hCCR3 (NM_001837), hCCR4 (NM_005508), hCCR5 (NM_000579), hCCR6 (NM_004367), hCCR7 (NM_001838), hCCR8 (NM_005201), hCCR9 (NM_006641), hCCR10 (AY429103), hCXCR1 (NM_000634), hCXCR2 (BC037961), hCXCR3 (NM_001504), hCXCR4 (AY728138), hCXCR5 (NM_032966), hCXCR6 (NM_006564), hCX3CR1 (NP_001328), and hXCR1 (NM_005283), mCXCR1 (AY749637), mCXCR2 (NM_009909), mCXCR3 (NM_009910), mCXCR4 (NM_009911), mCXCR5 (NM_007551), mCXCR6 (NM_030712), mCCR1 (NM_009912), mCCR2 (NM_009915), mCCR3 (NM_009914), mCCR4 (NM_009916), mCCR5 (NM_009917), mCCR6 (NM_009835), mCCR7 (NM_007719), mCCR8 (NM_007720), mCCR9 (NM_0099130), mCCR10 (AF215982), mCX3CR1 (NM_009987), and mXCR1 (NM_011798), and reported chicken cCCR2 (CAF28776), cCCR5 (BI393893, CAF28777), cCCR8L1(CAF28778), cCCR9 (CAF28781), cCXCR1 (AAG33964), cCXCR4 (NP_989948), and cXCR1 (CAF28779), were also retrieved from GenBank for comparisons.

Phylogenetic analyses of protein sequences of chicken, human, and mouse chemokines and chemokine receptors were based on the amino acid sequences using neighborjoining with options selected for bootstrap test, pairwise deletion and Poisson correction, using MEGA3 [35,36]. For ligand-receptor inference, the first 20 amino acids (leading peptide) of all chemokines were removed before the phylogenetic analysis and chicken CCLs were divided into two groups, one group located on Chromosomes 4 and 19 and the other from other chromosomes. Syntenies, phylogenetic trees, and sequence homologies were the combined information used for naming chicken chemokines and their cognate receptors according to the recommendations of the IUIS/WHO Subcommittee on Chemokine Nomenclature [37]. These chicken genes were named according to their closest predicted human or mouse orthologs if all information supports the nomenclature. If there was more than one chicken gene similar to a human and/or mouse gene, these gene was named as in the human and/or mouse followed by a letter with alphabet order. If a specific human or mouse ortholog could not be reliablely determined, the chicken genes were named according to a closest human or mouse ortholog followed by an "L" and a number based on the information available. This nomenclature also used the existing systematic names reported in the literature to avoid confusion. 
Table 2: Systematic names, chromosomal locations (kb), and putative identified cognate receptors of chicken chemokines'

\begin{tabular}{|c|c|c|c|c|}
\hline Nomenclature & Chromosomal location & Ligand name & Putative receptor & Chromosomal location \\
\hline CCLILI & $\operatorname{chr}|9: 4,49|-4,492$ & I-309/TCA & CCR8a and/or CCR8b & $\operatorname{chr} 2: 43,465-43,469$ \\
\hline CCLIL2 & $\operatorname{chr} 19: 4,493-4,495$ & & & chr2:4I,804-4I,8II \\
\hline CCL/MCP-LI & $\operatorname{chrl9:4,495-4,496}$ & MCP-? & & \\
\hline CCL/MCP-L2 & $\operatorname{chr} 19: 4,498-4,499$ & MCP-? & CCR2 & chr2:41,768-41,769 \\
\hline CCL/MCP-L3 & chr| 19:4,507-4,508 & MCP-? & & \\
\hline CCLI6 & $\operatorname{chr|9:258-26|}$ & $\mathrm{HCC}$ & & \\
\hline CCL3LI & $\operatorname{chr19:240-242}$ & MIP-I $\alpha$ & & \\
\hline CCL4LI & $\operatorname{chr} 19: 250-253$ & MIP-I $\beta$ & CCR5 & chr2:41,784-4I,786 \\
\hline CCL5 & $\operatorname{chr19:263-266}$ & RANTES & & \\
\hline CCLI7 & chrl I:768-77I & TARC & CCR4 & $\operatorname{chr} 2: 43,50 \mathrm{I}-43,503$ \\
\hline CCLI9 & chrZ_random:7,804-7,809 & MIP-3 $\beta$ & CCR7 & chr27_random:661-673 \\
\hline CCL2I & chrZ_random:7,810-7,810 & SLC & & \\
\hline CCL20 & chr9:4,1 19-4, 122 & MIP-3 $3 \alpha$ & CCR6 & chr3:38,589-38,596 \\
\hline Not found ${ }^{2}$ & & CCL25 & CCR9 & chr2:41,880-41,882 \\
\hline CXCL8b & chr4:5I,462-5I,466 & IL-8 & CXCR2 & chrUn:136,108-136,109 \\
\hline CXCL8a & chr4:5I,475-5I,479 & & $\mathrm{CXCRI^{3 }}$ & chrUn:25,460-25,462 \\
\hline CXCLI2 & chr6:18,184-18,195 & SDF-I & CXCR4 & chr7:3I,44I-3I,443 \\
\hline CXCLI3a & chr4:35,453-35,455 & BCA-? & & \\
\hline CXCLI3b & chr4:35,455-35,457 & BCA-? & CXCR5 & chr24:5,242-5,247 \\
\hline CXCLI3c & chr4:35,457-35,459 & BCA-? & & \\
\hline CXCLI4 & $\operatorname{chr}|3:| 4,231-14,239$ & BRAK & Unknown 4 & \\
\hline CXCLI5 & chr4:5I,500-5I,50। & Lungkine & Unknown 4 & \\
\hline $\mathrm{CX}_{3} \mathrm{CLI}$ & chrl I:758-764 & Fractalkine & $\mathrm{CX}_{3} \mathrm{CRI}$ & chr2:43,480-43,490 \\
\hline$X C L I$ & chrl:780,8I-78,086 & Lymphotactin & $X C R I$ & chr2:4I,83I-4I,833 \\
\hline
\end{tabular}

I The systematic naming, ligand naming, and putative receptors are according to [37] and [38].

${ }^{2}$ CCL25 was not identified in this study.

3 The ligand and receptor binding has been experimentally tested [39]

${ }^{4}$ The information is currently not available in humans or mice.

\section{Polymerase chain reaction (PCR) and DNA sequencing} Chicken EST or mRNA sequences were identified for all chemokine genes. All sequences contained complete putative open reading frames except for $\mathrm{CX}_{3} \mathrm{CL} 1$. However, partial chicken CX $_{3}$ CL1 gene sequences (BM426140, BI066258, and CR389767) were identified, with a gap of 123 nucleotides between the ESTs. Forward (TGTGACATCGGGAGTCGCTAC) and reverse (AAAATCCCCAGCGTTTGCTACT) PCR primers were used to amplify across the gap using cDNA prepared from white blood cells. PCR was performed as follows: An initial denaturation step at $94^{\circ} \mathrm{C}$ for $2 \mathrm{~min}$ and 35 cycles of denaturation, annealing, and extension at $94^{\circ} \mathrm{C}$ for 30 sec, $59^{\circ} \mathrm{C}$ for $45 \mathrm{sec}$, and $72^{\circ} \mathrm{C}$ for 1 min., and a final extension step was carried out at $72^{\circ} \mathrm{C}$ for $10 \mathrm{~min}$. Unincorporated nucleotides were removed from amplified PCR products using BioMax spin-50 mini-columns (Millipore, Billerica, MA). BigDye terminator cycle sequencing reaction kits and an ABI Prism 377XL DNA Sequencer (Applied Biosystems) were used for DNA sequencing.

\section{List of abbreviations}

Abbreviations: cCAF, chicken chemotactic and angiogenic factor; JSC, Jun-suppressed chemokine; SDF-1, stromal cell-derived factor-1; MCPs, monocyte chemoattractant proteins; MIPs, macrophage inflammatory proteins.

\section{Authors' contributions}

JW collected most of the data and drafted the manuscript. DLA contributed to the interpretation of the data and final approval of the manuscript. AY performed the DNA sequencing and assisted with the preparation of the manuscript. SHS and YJ designed computer programs to search chicken chemokine sequences in chicken EST database. JJZ provided the conception and design of the study, collected some of the data, conducted phylogenetic analysis, and revised the manuscript.

\section{Acknowledgements}

The authors sincerely thank Mr. Suresh Xavier for his assistance in setting up the chicken EST database for this study. This research project was financially supported by Life Science Task Force at Texas A\&M University. This research work should also be credited to all persons including the funding agencies who contributed to chicken genome and EST sequencing and the genome browser. Without the chicken genetic information, this research would have taken years and substantial funds to accomplish. The authors also greatly appreciate the inputs from the reviewers of this manuscript. 


\section{References}

I. Olson TS, Ley K: Chemokines and chemokine receptors in leukocyte trafficking. Am J Physiol Regul Integr Comp Physiol 2002, 283:R7-R28.

2. Onuffer J, Horuk R: Chemokines, chemokine receptors and small-molecule antagonists: recent developments. Trends Pharmacol Sci 2002, 23:459-467.

3. Zlotnik A, Yoshie O: Chemokines: a new classification system and their role in immunity. Immunity 2000, I 2:121-127.

4. Murphy PM: Chemokines. In Fundamental Immunology 5th edition. Edited by: William EP. New York: Lippincott Williams \& Wilkins; 2003:80I-840.

5. Van Coillie E, Van Damme J, Opdenakker G: The MCP/eotaxin subfamily of CC chemokines. Cytokine Growth Factor Rev 1999, 1 0:6 I-86.

6. Laing KJ, Secombes CJ: Chemokines. Dev Comp Immunol 2004, 28:443-460.

7. Nomiyama H, Mera A, Ohneda O, Miura R, Suda T, Yoshie O: Organization of the chemokine genes in the human and mouse major clusters of $\mathrm{CC}$ and $\mathrm{CXC}$ chemokines: diversification between the two species. Genes Immun 200 I, 2: I I0-I I3.

8. Forssmann U, Magert HJ, Adermann K, Escher SE, Forssmann WG Hemofiltrate CC chemokines with unique biochemical properties: HCC-I/CCLI4a and HCC-2/CCLI5. J Leukoc Biol 200I, 70:357-366

9. Kaiser P, Hughes S, Bumstead N: The chicken 9E3/CEF4 CXC chemokine is the avian orthologue of IL8 and maps to chicken chromosome 4 syntenic with genes flanking the mammalian chemokine cluster. Immunogenetics 1999, 49:673-684.

10. Murphy PM: Chemokine Receptors: Cloning Strategies. Methods 1996, 10:104-118.

I I. Horuk R: Chemokine receptors. Cytokine Growth Factor Rev 200I, I 2:313-335.

12. Petrenko O, Ischenko I, Enrietto PJ: Characterization of changes in gene expression associated with malignant transformation by the NF-kappaB family member, v-Rel. Oncogene 1997, | 5:167|-1680.

13. Petrenko O, Ischenko I, Enrietto PJ: Isolation of a cDNA encoding a novel chicken chemokine homologous to mammalian macrophage inflammatory protein-I beta. Gene 1995, 160:305-306.

14. Sugano S, Stoeckle MY, Hanafusa H: Transformation by Rous sarcoma virus induces a novel gene with homology to a mitogenic platelet protein. Cell 1987, 49:321-328.

15. Li QJ, Lu S, Ye RD, Martins-Green M: Isolation and characterization of a new chemokine receptor gene, the putative chicken CXCRI. Gene 2000, 257:307-3I7.

16. Hughes S, Haynes A, O'Regan M, Bumstead N: Identification, mapping, and phylogenetic analysis of three novel chicken CC chemokines. Immunogenetics 200I, 53:674-683.

17. Liang TS, Hartt JK, Lu S, Martins-Green M, Gao JL, Murphy PM: Cloning, mRNA distribution, and functional expression of an avian counterpart of the chemokine receptor/HIV coreceptor CXCR4. J Leukoc Biol 200I, 69:297-305.

18. Smith J, Speed D, Law AS, Glass EJ, Burt DW: In-silico identification of chicken immune-related genes. Immunogenetics 2004, 56:122-133.

19. Hartl M, Bister K: Suppression of genes in jun-transformed avian fibroblasts. in press.

20. Rossi D, Sanchez-Garcia J, McCormack WT, Bazan JF, Zlotnik A: Identification of a chicken "C" chemokine related to lymphotactin. J Leukoc Biol 1999, 65:87-93.

21. Sick C, Schneider K, Staeheli P, Weining KC: Novel chicken CXC and CC chemokines. Cytokine 2000, I2: I81-186.

22. Morroll S, Bumstead N: Identification and characterisation of the primary C-C chemokine receptor gene cluster in chicken. in press.

23. Read LR, Cumberbatch JA, Buhr MM, Bendall AJ, Sharif S: Cloning and characterization of chicken stromal cell derived factorI. Dev Comp Immunol 2005, 29: |43-52.

24. Kaiser $P$, Hughes $S$, Bumstead N: The chicken 9E3/CEF4 CXC chemokine is the avian orthologue of IL8 and maps to chicken chromosome 4 syntenic with genes flanking the mammalian chemokine cluster. Immunogenetics 1999, 49:673-684.

25. UCSC Genome Brower [http://genome.ucsc.edu]
26. Huang $X$, Madan A: CAP3: A DNA Sequence Assembly Program. Genome Research 1999, 9:868-877.

27. CAP3 Sequence Assembly Program [http:// deepc2.zool.iastate.edu/aat/cap/cap.html]

28. Open Reading Frame Finder [http://www.ncbi.nlm.nih.gov/gorf/ gorf.html]

29. Altschul SF, Madden TL, Schäffer AA, Zhang J, Zhang Z, Miller W, Lipman DJ: Gapped BLAST and PSI-BLAST: a new generation of protein database search programs. Nucleic Acids Research 1997 , 25:3389-402.

30. NCBI BLAST Program [http://www.ncbi.nlm.nih.gov/BLAST/]

31. NCBI Genbank Database [http://www.ncbi.nih.gov/Genbank]

32. Higgins DG, Thompson JD, Gibson TJ: CLUSTAL W: improving the sensitivity of progressive multiple sequence alignment through sequence weighting, position-specific gap penalties and weight matrix choice. Nucleic Acids Res 1994, 22:4673-4680.

33. Multiple sequence alignment program [http://www.ebi.ac.uk/ clustalw]

34. SMART Program [http://194.94.45.21//smart/show motifs.pl]

35. Kumar S, Tamura K, Nei M: MEGA3: Integrated Software for Molecular Evolutionary Genetics Analysis and Sequence Alignment. in press.

36. MEGA 3 Program [http://www.megasoftware.net/]

37. Bacon K, Baggiolini M, Broxmeyer H, Horuk R, Lindley I, Mantovani A, Maysushima K, Murphy $P$, Nomiyama $H$, Oppenheim J, Rot A, Schall T, Tsang M, Thorpe R, Van Damme J, Wadhwa M, Yoshie O, Zlotnik A, Zoon K: Chemokine/chemokine receptor nomenclature. J Interferon Cytokine Res 2002, 22: I067-I068.

38. Murphy PM: International Union of Pharmacology. XXX. Update on chemokine receptor nomenclature. Pharmacol Rev 2002, 54:227-229.

39. Li QJ, Yao M, Dueck M, Parpura V, Martins-Green M: cCXCRI is a receptor for cIL8 (9E3/cCAF) and its $\mathrm{N}$ - and C-terminal peptides and is also activated by hIL8 (CXCL8). J Leukoc Biol 2005, 77:421-431.
Publish with Biomed Central and every scientist can read your work free of charge

"BioMed Central will be the most significant development for disseminating the results of biomedical research in our lifetime. "

Sir Paul Nurse, Cancer Research UK

Your research papers will be:

- available free of charge to the entire biomedical community

- peer reviewed and published immediately upon acceptance

- cited in PubMed and archived on PubMed Central

- yours - you keep the copyright
BioMedcentral 